\title{
Investigating the Effects of Pentanol and Biodiesel Blends on the Performance and Emission Characteristic of Compression Ignition Engine
}

\author{
I. U. Ibrahim*, M. Idris, I. A. Hussain, M. U. Kaisan, I. Ajunwa, A. Shitu \\ Department of Mechanical Engineering, Ahmadu Bello University, Zaria, Nigeria.
}

ABSTRACT: Emissions from use of fossil fuels have consistently posed significant threat to the environment and wellbeing of man. This has prompted several studies aimed at finding solution to the emissions and their effects. The aim of this research is to investigate the effect of adding pentanol and biodiesel from Moringa Oleifera seed to pure diesel content of $70 \%$ by volume. pentanol and biodiesel make up the remaining 30 percent by volume and were also varied, with pentanol percentage being increased from 2 percent to 8 percent so as to carefully monitored the effects of adding pentanol while the Moringa oleifera biodiesel made up the balance for the $30 \%$. These blends were labelled according to the percentage composition of biodiesel and pentanol (B28P2, B26P4, B24P6, B24P6, and B22P8). The physicochemical properties of all blends such as viscosity, density, pour point, acid value and iodine value determined. From the result of the engine performance and emission tests, B24P6 blend has been noted to have the best engine performance parameters, haven shown the best engine brake power of $19.787 \mathrm{~kW}$, and with the highest engine brake thermal efficiency of $19.78 \%$. While in term of engine emission, B22P8 blend, have the lowest Nitrogen oxide (NOx) emission, with a value of $82.4994 \mathrm{ppm}$ which is about 3\% lower than that of pure diesel, while B26P4 have the lowest carbon monoxide (CO) emission among all the samples tested with value of $6.1556 \mathrm{ppm}$ which is about $58 \%$ lower than that of Petro diesel. However, blends appeared to have good brake mean effective pressure except for B22P8 which have the lowest BMEP, that's about 2.8\% lower than that of Petro diesels. Conclusively, the addition of Moringa oleifera biodiesel with pentanol improved the diesel quality, yielding good improvement in engine performance and emission.

KEYWORDS: Diesel, biodiesel, pentanol, biofuel blends, Moringa oleifera seed, engine emissions

\section{INTRODUCTION}

The growing need to find an alternative source of energy to fossils fuels due to the increasing depletion challenge of fossil fuels is still on-going (Kaisan et al., 2020a). Alternative energy sources such as biodiesel have been reported to have similar physico-chemical properties to fossil diesel and have less greenhouse gas emission than diesel from fossils (Muralidharan \& Vasudevan, 2011; Ituen \& Ijioma, 2010).).Biodiesel produced from edible and non-edible feedstock could serve as a substitute to fossil diesel and reduce the emissions that pose great challenges to the health and social well-being of man (Kaisan et al., 2017, Kaisan et al., 2018). However, the search of these alternative sources that meet the requirement comes at a great cost. Bergman and Golovitchev, (2007) reported that, about $\$ 8$ billion was spent by some companies in the quest for searching new energy source that will replace the current fossils fuels sources.

Biodiesel fuels are highly rated replacements for fossils fuels (Amos et al., 2016; Kaisan et al., 2017). Atabani et al., (2014) reported that It is expected that, by 2050, biodiesel will provide about $27 \%$ of the world total transports fuels, which will translate to reducing about $2.1 \mathrm{Gt}$ of $\mathrm{CO}_{2}$ emissions in a year (Damanik et al., 2018) explained that one of the alternative petroleum based fuels is biodiesel which is derived from different feed stocks like vegetable oils, animal fats and waste cooking oils. Producing Biodiesels from edible row material like soya beans have challenges of its own, but the most important of all is the threat it has on food security, and also high production cost, these are the main problems that hindered its commercialization and wide usage as an alternative fuel.

Da Silva et al., (2010) studied the physicochemical properties of biodiesel produced from Moringa oleifera seeds and suggested that Moringa oleifera, biodiesel can be used as fuels in diesel engine, especially as a blend with petrodiesel. Mofijur et al., (2015) studied the physicochemical properties of Moringa oleifera biodiesel and its blends, in the research, a blend of moringa biodiesel and diesel with a composition of $10 \%$ moringa biodiesel and $90 \%$ Petro diesel was investigated; the results shows that addition of moringa biodiesel to diesel affected the viscosity of the diesel, in which he reported a value 
of $5.4 \mathrm{~mm}^{2} \mathrm{~s}^{1}$ and it also affects other properties of the fuels like density, with a value of $883 \mathrm{kgm}^{3}$, flash point, cloud point and pour point were all said to be improved. Mofijur et al., (2014) compared and evaluated the performance and emission characteristics of Moringa oleifera and Palm oil-based biodiesel, their findings shows that carbon monoxide, and hydrocarbon emissions reduce by about $13.17 \%$ and $14 \%$ respectively when compared with Petro diesels, for the two biodiesels tested, in terms of engine performances, both the two biodiesel have higher specific fuel consumptions then Petro diesels, with moringa oleifera biodiesels shows an increase of about $5.13 \%$ in engine brake specific fuel consumption. While with a $10 \%$ Moringa oleifera biodiesel shows an increase in NOx emission to an extent of about of $8 \%$, the same happened with the carbon dioxide, which also increases.

In an experiment to investigate the effect of pentanol addition on the performance and emission of biodiesel from the cashew nut shell by Devarajan et al., (2017), it was found out that addition of pentanol significantly reduced engine emission, far less than that of pure diesel at all engine loads. Demirbas et al., (2016) reported the effect of pentanol addition on the performance and engine emission of diesel engines fueled with palm oil biodiesel, the findings revealed that, the addition of higher alcohol or specifically pentanol resulted in more smooth combustions and reduces engine emission of hydrocarbons, nitrogen oxides, and carbon monoxide to about 9.3\% as compared with neat palm oil diesel which has higher emission.

Campos-Fernandez et al., (2013) investigated the performance of diesel engine fueled with pentanol/diesel blend without any engine modification, in the research, sample blends with pentanol percentage of $10,15,20$, and 25 by volume of the fuels was prepared, and results showed insignificant change in the engine performance (brake power, brake thermal efficiency, and specific fuel consumption of the engine). They also explained that, despite the fact that, there is no any engine modification, the performance of the engine was good, thereby suggesting that pentanol/ diesel fuels can be considered as a possible contender to replace diesel fuels. Atmanli, (2016) compared the performance and emission of a diesel engine when fueled with diesel-waste oil biodiesel and propanol, n-butanol or 1-pentanol blends; results showed that blends of pentanol have higher engine specific fuel consumptions at all engine loads tested, and their exhaust gas temperature was also higher than those of the diesel - biodiesel blends.

The results, also established that all blends of the alcohols have less NOx emissions, but increases the emission of carbon monoxides, significantly, with the least average increase of $12.60 \%$ observed by D40B40Pn20 blend. Wei et al., (2014), investigated the effects of adding n-pentanol on the performance and emission of diesel engines, experimental results showed that, addition of n-pentanol alcohol results in longer ignition delay and an increase in the rate of heat release rate from premixed combustion phase. Pertaining to the engine performance parameters, brake specific fuel consumption increases as pentanol increases, while engine brake thermal efficiency did not significantly vary. The results show an increase in both NOx, HC, and CO. emissions. The aim of this study is to investigate the effect of pentanol addition in dieselbiodiesel blends in compression ignition engine.

\section{MATERIALS AND METHODS}

\section{A. Materials and Equipment}

A four-stroke air-cooled horizontal single-cylinder diesel engine (specifications on Table 1) was used to carry out the experimental tests. The gas analyzer used for the experiments is manufactured by Nanhua Guangdong, China and its specifications are presented in Table 2:

Table 1: Engine specifications.

\begin{tabular}{ll}
\hline Engine parameter & Specification \\
\hline Engine type & Horizontal single cylinder \\
& four stroke air cooled system \\
Rated speed $(\mathrm{rpm})$ & 2600 \\
Rated power $(\mathrm{kW})$ & 2.43 \\
Net weight $(\mathrm{kg})$ & 40 \\
Compression ratio & $205-22$ \\
Method of cooling & Air cooled \\
Model & Super $165 \mathrm{~F}$ \\
Serial no & 796581 \\
Overall dimensions $(\mathrm{mm})$ & $518 \times 321 \times 423$ \\
\hline
\end{tabular}

Table 2: Specification of gas analyzer.

\begin{tabular}{ll}
\hline Details & Specifications \\
\hline Brand name & Nanhua \\
Power supply & Ac $220 \mathrm{v}-/+10 \%, 50 \mathrm{HZ}-/+1 \mathrm{HZ}$ \\
Model number & NHA-506EN \\
Net weight & $10 \mathrm{~kg}$ \\
Test & $\mathrm{HC}, \mathrm{CO}, \mathrm{CO}_{2}, \mathrm{O}, \mathrm{NO}$ \\
Warm up time & $10 \mathrm{~min}$ \\
\hline
\end{tabular}

\section{B. Methodology}

\section{1.) Blending}

The blends were prepared with 70 per cent of conventional diesel, $2 \%$ of pentanol and $28 \%$ of Moringa biodiesel were added to make up the first blend for the experiment, and the blend was labelled B28P2. The convectional diesel was maintained at $70 \%$ throughout the experiment, while the rest of the blends were prepared by increasing the pentanol volume in increasing order of $2 \%$ while biodiesel was reduced by the same percentage.

Table 3: Nomenclature of samples.

\begin{tabular}{clcccc}
\hline S/N & $\begin{array}{l}\text { Nomenclature of } \\
\text { samples }\end{array}$ & $\begin{array}{c}\text { \% of } \\
\text { diesel }\end{array}$ & $\begin{array}{c}\text { \% of } \\
\text { biodiesel }\end{array}$ & $\begin{array}{c}\text { \% of } \\
\text { pentanol }\end{array}$ \\
\hline 1 & D100 & or & 70 & 28 & - \\
2 & $\begin{array}{l}\text { D70B28P2 } \\
\text { B28P2 }\end{array}$ & or & 70 & 26 & 4 \\
3 & $\begin{array}{l}\text { D70B26P4 } \\
\text { B26P4 }\end{array}$ & or & & & \\
4 & $\begin{array}{l}\text { D70B24P6 } \\
\text { B24P6 }\end{array}$ & or & 70 & 24 & 6 \\
5 & $\begin{array}{l}\text { D70B22P8 } \\
\text { B22P8 }\end{array}$ & or & 70 & 22 & 8 \\
\hline
\end{tabular}




\section{2.) Experimental Procedure for Performance and Emission Tests}

The performance and emission characterization were carried out on four strokes single cylinder horizontal diesel engine. Before initiating the test, the engine was started and warmed up with pure diesel to attain steady state at constant torque. The experiment was initially conducted with diesel and used as the baseline and subsequently with B28P2, B26P4, $\mathrm{B} 24 \mathrm{P} 6$, and $\mathrm{B} 28 \mathrm{P} 8$ at $6 \mathrm{Nm}$ engine torque. The experimental test was carried out at ambient conditions of 1 bar and $35{ }^{\circ} \mathrm{C}$. The data for the performance parameters and the emission were recorded. The emissions measured were $\mathrm{HC}, \mathrm{CO}, \mathrm{CO}_{2}$, and oxides of nitrogen (NOx). The brake power, $B_{p}$, the brake mean effective pressure, $P m$, the specific fuel consumption, $S F C$, and the brake thermal efficiency, Bthe, were calculated using Eqs. (1) through (4) respectively.

$$
B_{P}=\frac{2 \pi N T}{60}
$$

where $B p$ is the brake power

$N$ is the angular speed

$T$ is the torque

$$
P m=\frac{60000 B P}{L A N K}
$$

where

$A$ is piston area

$L$ is the stroke

$N$ is the speed

$K$ is the number of cylinders

$$
S F C=\frac{M F}{B P}
$$

where

$M F$ is the rate of flow

$B p$ is the brake power

$$
\text { Bthe }=\frac{B P}{M F \times Q}
$$

where

$M F$ is the mass of fuel supplied

$\mathrm{Q}$ is the lower heating value

\section{3.) Engine Emission Test}

The emission test was carried out using a gas analyzer, which measured the concentration of exhaust species at constant torque of $6 \mathrm{Nm}$. The test was carried out on all the five samples and the readings were recorded.

\section{4.) Test of properties of the blend}

This is the property of the fluid which determines its resistance to shear stress. It is also a measure of internal fluid friction which causes resistance to flow. The viscosity of biodiesel blend was measured using Brookfield viscometer. $200 \mathrm{ml}$ was charged into a beaker at room temperature its content was then poured in the spindle which was then kept in the same temperature, it is then lowered in such a way to avoid touching the bottom of the beaker. The reading from the viscometer was recorded.

Density is the ratio of the specific mass of the substance to the specific volume of standard fluid. The densities of the samples were obtained using Eq. (5). $5 \mathrm{~cm}^{3}$ capacity empty beaker was weighed and recorded as $\mathrm{M}_{1}$, and then filled with a blended sample weighed again and recorded as $\mathbf{M}_{2}$.

$$
\text { Density }=\frac{M_{2}-M_{1}}{\text { Volume of Sample }}
$$

\section{3.) Iodine Value}

Iodine value gives the amount of unsaturation in the fuel. The degree of unsaturation is represented by the double-bonds, this implies that, the more the double bonds in the sample, the higher the iodine value. The Iodine value is computed using Eq. (6). Where B is the sodium thiosulfate solution volume in $\mathrm{mL}$ used in the titration of the blank; $\mathrm{A}$ is the sodium thiosulfate solution volume in $\mathrm{mL}$ used in the sample titration; $\mathrm{N}$ is the concentration of the sodium thiosulfate solution in mol $\mathrm{L}^{-1} \mathrm{~W}$ is the weight in grams. Tubino et al., (2013)

$$
I V=\frac{(B-S) \times 12.69 \times N}{W}
$$

\section{RESULTS AND DISCUSSION}

\section{A. Results of Physicochemical Properties}

\section{1.) Viscosity}

It can be seen from Figure 1 below, B28P2 have a viscosity of 0.8 poise, while B26P4, B24P6, and B22P8 Samples have the same viscosity of 0.5 poise, and it's the least viscosity as compared with the viscosity of conventional diesel D100 which has a value of 1.2 poise. This is because the viscosity of the pentanol is less than that of diesel and the biodiesel, therefore adding pentanol into the blend of diesel and biodiesel reduces the blend viscosity. It was also noted that the viscosity tends to be stable despite the addition of more pentanol this is because the viscosity of the blends cannot go below that of the pentanol (i.e. B26P4 to B22P8).

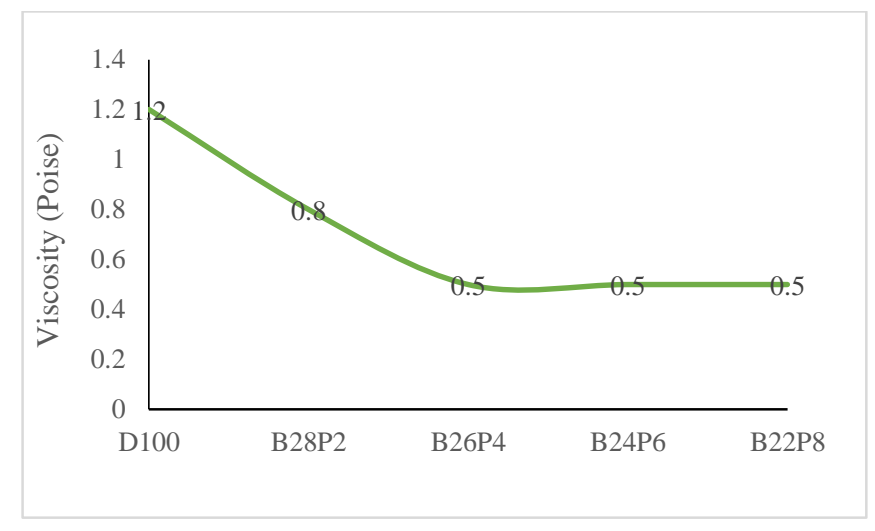

Figure 1: Viscosity of the samples.

\section{2.) Density}

Figure 2 shows the value of density for each blend, where it appears that sample with the highest density is the Petro diesel D100. Also, a similar trend of results as in the case of the viscosity occurs where the addition of pentanol to a $4 \mathrm{vol}$. $\%$ drastically affect the blend density, but despite more addition of pentanol up to $8 \mathrm{vol}$. \%, very little change was 
noticed. This shows that the change in the density was brought about by the addition of pentanol, and indicates that, 2 vol. \% addition of pentanol is enough since very little change was observed with the addition of more pentanol. This result is in agreement with the results obtained by Mofijur et al.,(2015).

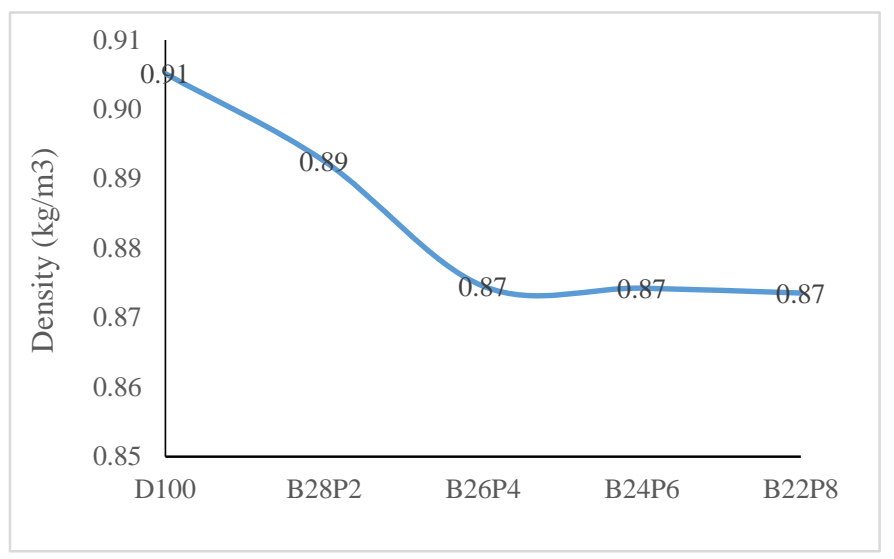

Figure 2: Density of the samples.

\section{3.) Iodine value}

From the result of iodine value test presented in figure 3 , it can be seen that B26P4, has the lowest iodine value among all the blends tested. It appears also that, the addition of more pentanol beyond the 4 vol. \% increases the iodine value of the fuels blends. As such B22P8 has the highest iodine value among all the samples blends tested. This result indicates that additions of pentanol to any percentages above 4 vol. \% increases the degree of fuels unsaturation.

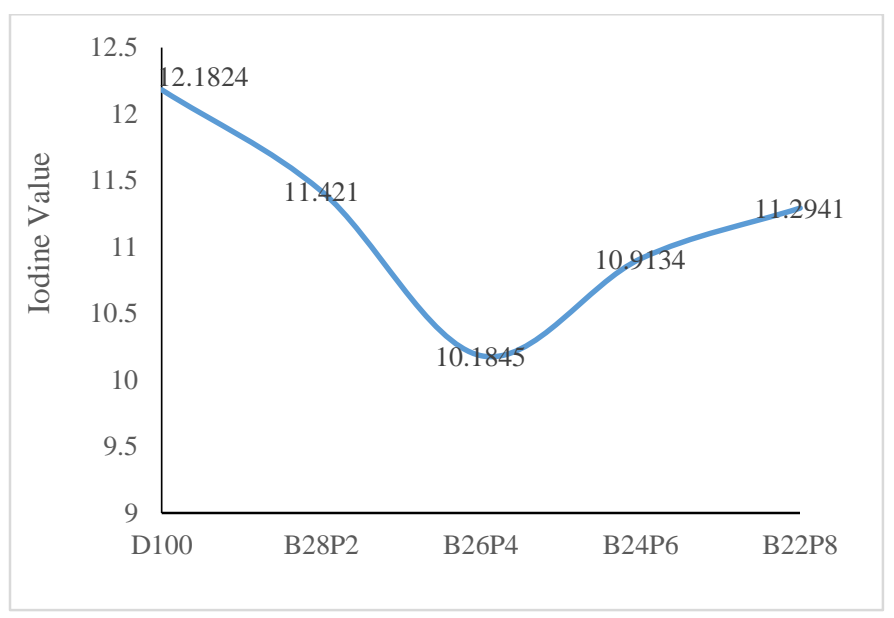

Figure 3: Iodine values of the samples.

\section{4.) Acid value}

From Figure 4, it shows that the addition of pentanol to a volume percentage of $4 \mathrm{vol} . \%$ also drops the acidic value of the fuel blends to the lowest value, which is a little lower than the value of pure diesel, but when the pentanol percentage was increased from 4 vol. \% to 8 vol. \%, acidic value rises. This clearly indicates the effects of pentanol addition on the acid value of the fuels blends.

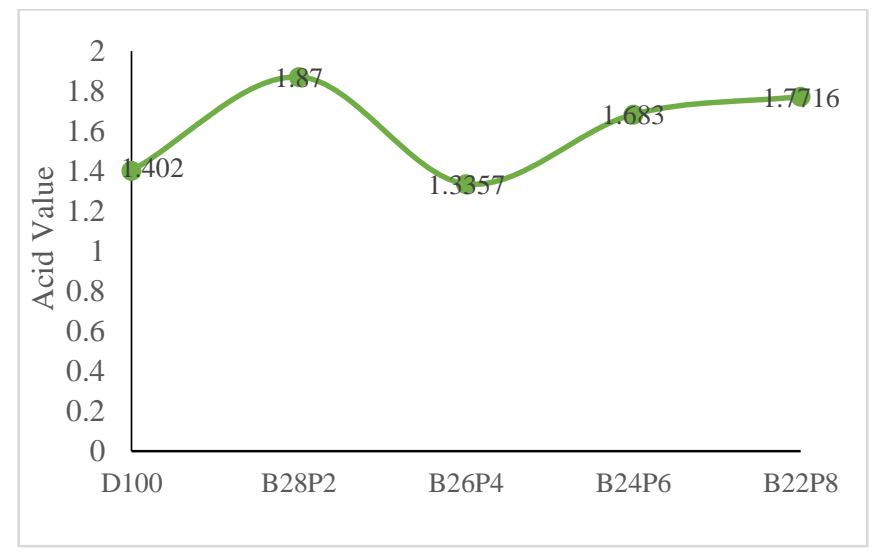

Figure 4: Acid value of samples.

\section{5.) Cloud point}

The cloud can be defined as that lowest temperature at which biodiesel will start forming solid crystals Lanjekar et al., (2016). experimental results show that the addition of Moringa Oleifera biodiesel and pentanol affects the cloud point of the fuel blends. When pentanol percentage reaches 8 vol. \%, in B22P8 blend, the cloud point temperature recorded was about $66 \%$ higher than the cloud temperature of the pure diesel D100, and it's the lowest cloud point temperature recorded among all the blends. The B26P4 blend has the highest cloud point. It is believed that pentanol addition has affected the fuels cloud point temperature significantly.

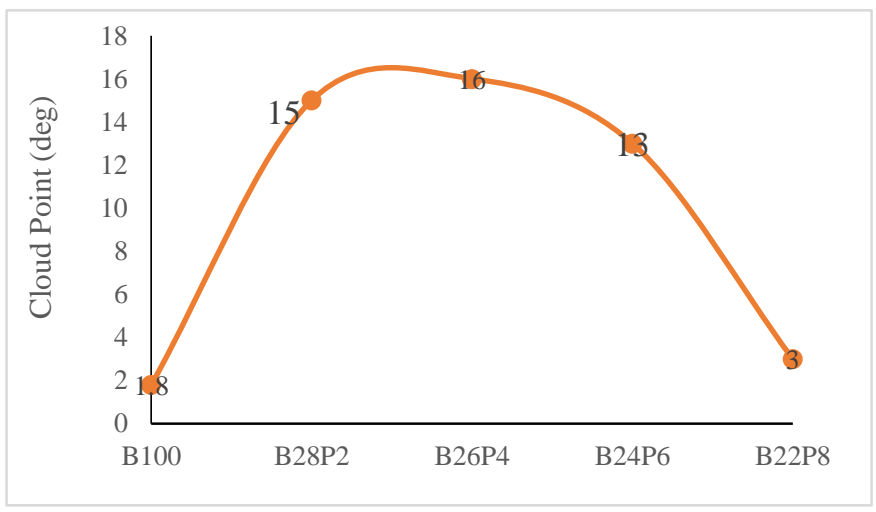

Figure 5: Cloud point of samples.

\section{Pour point}

Pentanol addition to the blends of conventional diesel and Moringa Oleifera biodiesel was seen to have an effect on the blends pour point temperature. The B24P6 blend appeared to have the lowest pour point temperature, $\left(2^{\circ} \mathrm{C}\right)$ while blend $\mathrm{B} 26 \mathrm{P} 4$ and $\mathrm{B} 28 \mathrm{P} 2$, have the same pour point temperature of 3 ${ }^{\circ} \mathrm{C}$ which is less than that of the pure diesel tested. At the point pentanol percentage reach 8 vol. \%, pour point temperature rises significantly to the highest level, therefore it was noted that addition of pentanol and reducing biodiesel fuels content in the blends, causes an increase in the pour point temperature of the blends. 


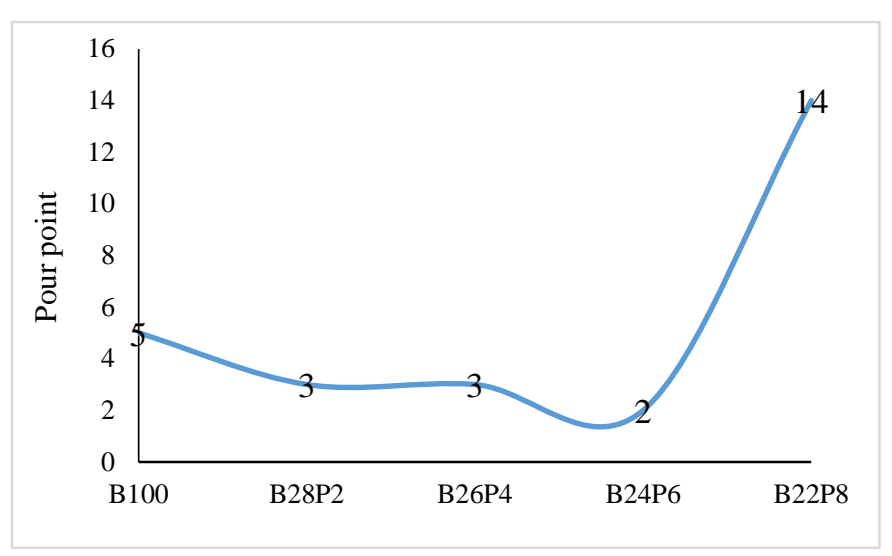

Figure 6: Pour point of the samples.

\section{B. Determination of Engine Performance}

\section{1.) Brake power}

From the engine test result presented in figure 7 , it can be seen that B24P6 has the highest engine brake power, while B28P2, B26P4 blends portrayed the lowest. Despite having 8 vol. \% of pentanol B22P8 blend has less brake power than B24P6. This is due to the fact that biodiesels have about $12 \%$ high oxygen content than Petro diesels, which is very significant in improving combustion efficiency, though pentanol has certain amount of oxygen, but reducing biodiesel in the blends affect the engine combustion, which courses drops in engine brake power.

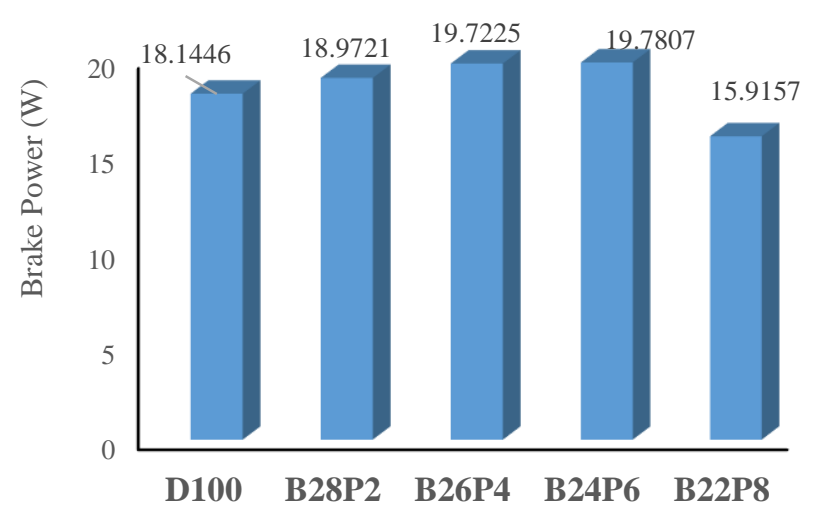

Figure 7: Brake power of the samples.

\section{2.) Break mean effective pressure (BMEP)}

The engine brake mean effective pressure result is presented in figure 8 , it can be observed that the addition of Moringa oleifera biodiesel and pentanol to convectional diesel fuel has significantly influenced the engine brake mean effective pressure. All the blends appeared to have a higher BMEP than the pure convectional diesel D100.

\section{3.) Specific fuel consumption}

From the experimental results shown in figure 9, its shows that addition of pentanol led to an increase in specific fuel consumptions to an extent of about $8 \%$ for B24P6 blend when compared with pure diesel, which the blend that has the highest increase in specific fuel consumptions, but as the

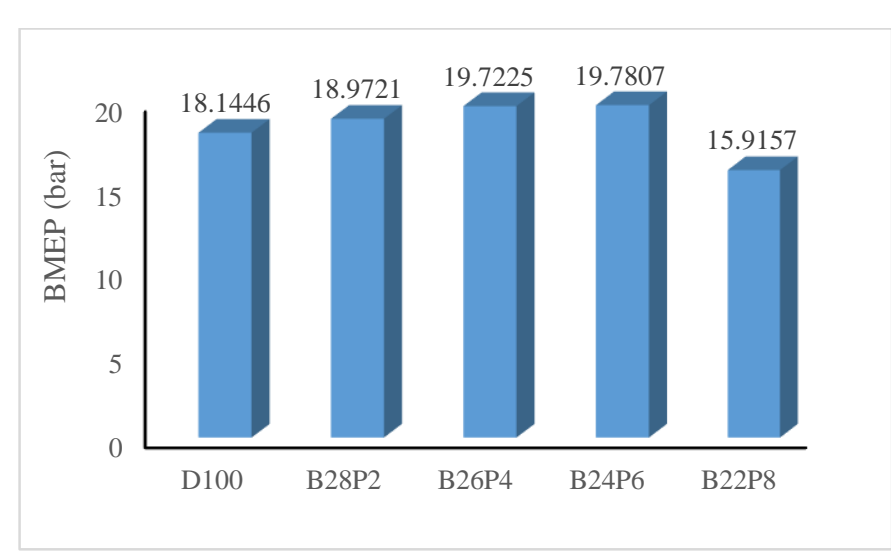

Figure 8: Brake mean effective pressure of the samples.

percentage of pentanol addition reach $8 \%$ by volume in $\mathrm{B} 22 \mathrm{P} 8$ sample, specific fuel consumptions reduced, it was acknowledge that, adding pentanol to an amount equal or above $8 \%$ by volume of the blend reduces engine specific fuel consumption, which shows that the continued addition of pentanol beyond the 8 vol. \% would not necessarily yield any difference, the difference shown between the pure diesel and the blend is enough to agree that there is a significant reduction in fuels consumptions by the engine.

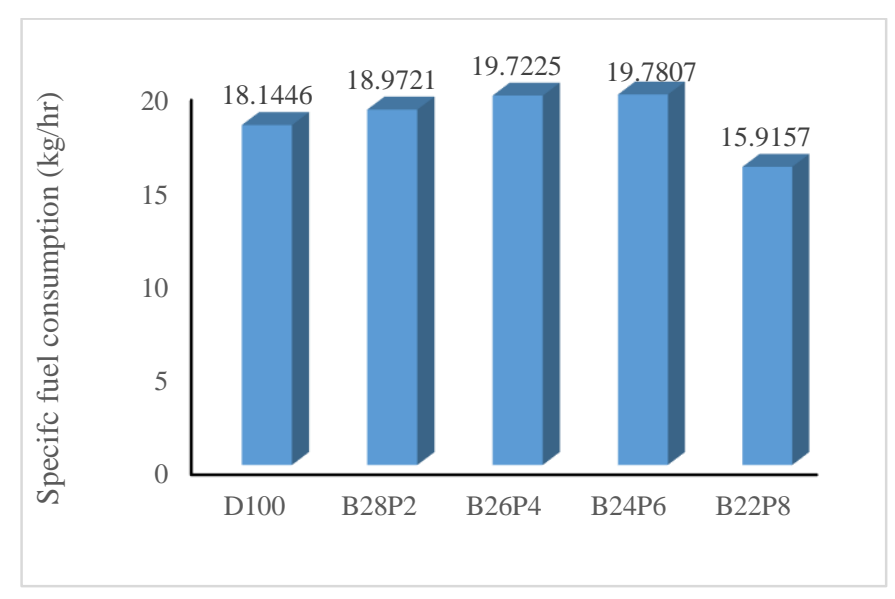

Figure 9: Specific fuel consumption of the samples.

\section{4.) Brake thermal efficiency}

Brake thermal efficiency is a measure of how effectively the heat content of a fuel is converted into mechanical power by the engine (Ashok et al., 2019). The effect of adding pentanol to the diesel-biodiesel blends can be inferred from Figure 10. Where engine brake thermal efficiency increases with about $4.5 \%$ when $\mathrm{B} 28 \mathrm{P} 2$ was used, among all the blends it was B26P6 that has the highest brake thermal efficiency, with an increase of about $9.0 \%$ over the pure diesel. This shows that the blend of diesel-biodiesel and pentanol have better engine Brake thermal efficiency than the pure diesel. 


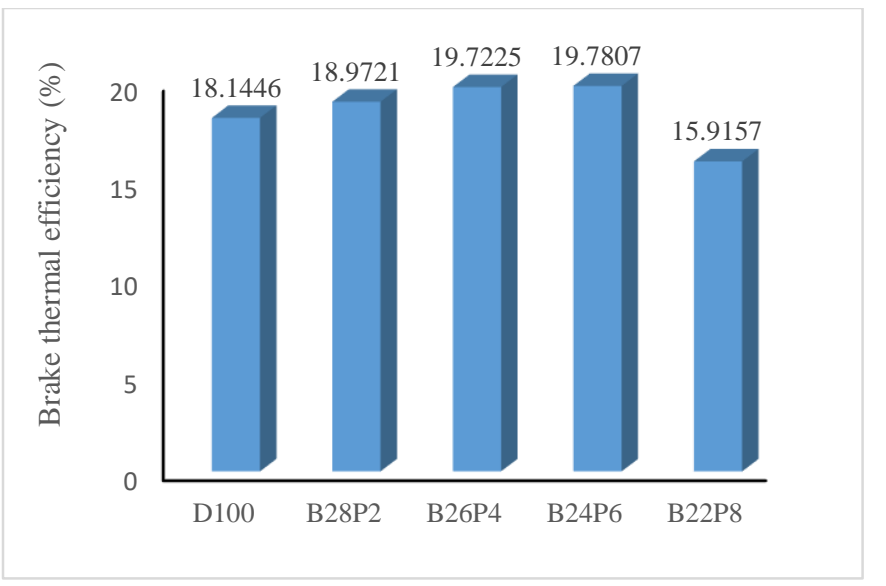

Figure 10: Brake thermal efficiency of the samples.

\section{Emission Test Result}

\section{1.) Exhaust temperature}

Figure 11 shows the variations of exhaust temperature for the respective blends, no much difference was noticed, except with the blend B22P8 which has a very low exhaust temperature when compared with the rest of the sample blends.

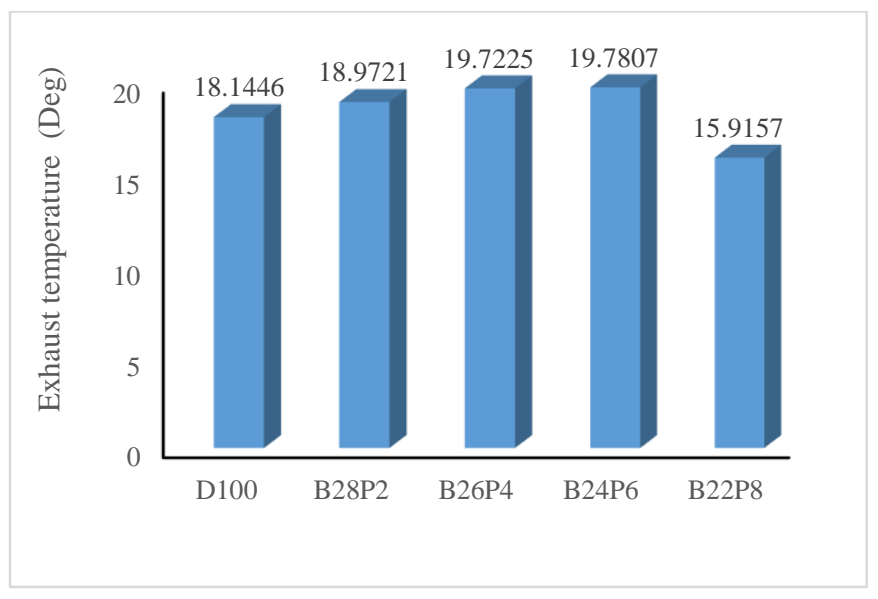

Figure 11: Exhaust temperature of the samples.

\section{2.) Hydrocarbons $(\mathrm{HC})$}

Hydrocarbons are compounds consisting of hydrogen and carbon. hydrocarbon emission is a result of unburnt hydrocarbons due to incomplete combustion (Kaisan et al., 2020b; kaisan et al., 2020c). despite the addition of pentanol which is an oxygenated compound, and biodiesel which has about $12 \%$ more oxygen content than pure diesel, still their emissions rises, higher than the pure diesel more especially when the pentanol percentage in the blend reaches 8 vol. \%, This is attributed to the high carbon content in both pentanol and biodiesel. From the result depicted in figure 12, blend $\mathrm{B} 28 \mathrm{P} 2$ has less $\mathrm{HC}$ emission as the pentanol percentage rises, $\mathrm{HC}$ emission also increases. This shows that reduction in biodiesel content and increasing pentanol does not reduce $\mathrm{HC}$ emissions, but rather increase it.

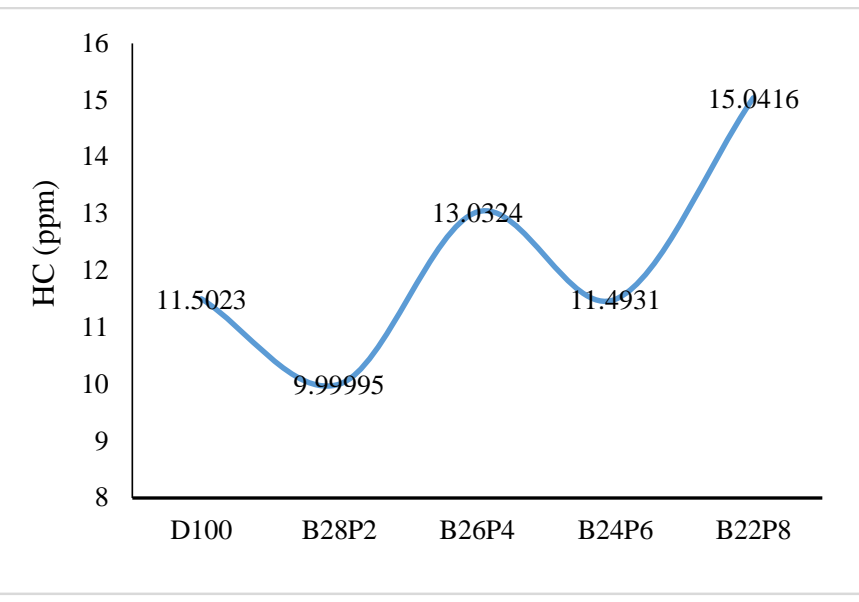

Figure 12: Hydrocarbon of the blends.

\section{3.) Nitrogen $\left(\mathrm{NO}_{\mathrm{X}}\right)$ emission}

NOx is the generic term for the oxides of nitrogen such as Nitric oxide (NO) and Nitrogen dioxide $\left(\mathrm{NO}_{2}\right)$. Oxides of nitrogen are produced in the engine due to the combustion of air which contains some percentage of nitrogen and oxygen. Due to the presence of hydroxyl functional group in pentanol molecules $(\mathrm{OH})$, there is high tendency of steam formation during combustion reaction, this will greatly reduce NOx emission. From the result shown in figure 13, its shows that addition of pentanol to a percentage level of $8 \%$ has greatly reduced NOx emission from the engine.

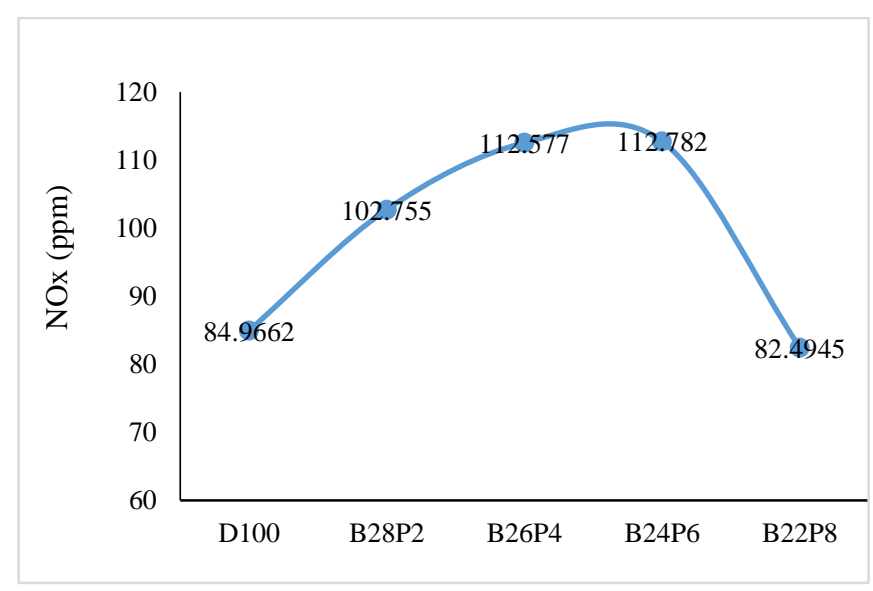

Figure 13: Nitrogen Oxide emissions.

\section{4.) Carbon dioxide $\left(\mathrm{CO}_{2}\right)$}

The formation of carbon dioxide in the engine indicates complete combustion of the fuel in the combustion chamber (kaisan et al., 2020d). Figure 14 shows that $\mathrm{CO}_{2}$ emission from the engine has been reduced due to the additions of Moringa oleifera biodiesel and pentanol. This is due to the increase in the carbon content in the fuel blends, which results from the pentanol and biodiesel, because pentanol is also a high carbon fuels even though it has some significant amount of oxygen, its carbon content effect the combustion process by increasing carbon monoxide and Hydrocarbons Emission at high pentanol percentages, and also reducing the $\mathrm{CO}_{2}$ as shown in the Figure 
14 were $\mathrm{CO}_{2}$ emission for $\mathrm{B} 22 \mathrm{P} 8$ reduce to about $12.3 \%$ as compared to pure Petro diesels.

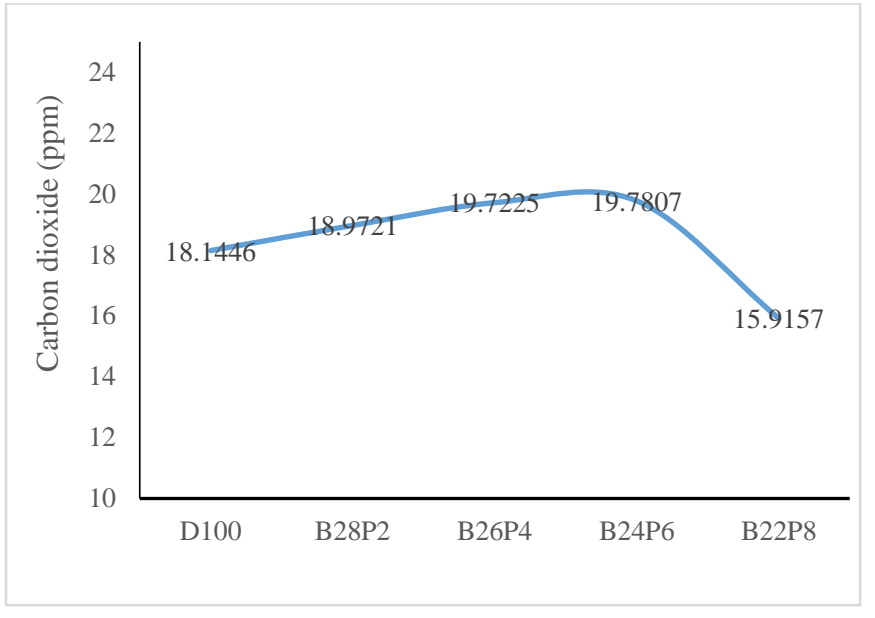

Figure 14: Carbon dioxide of the blends.

\section{5.) Carbon monoxide ( $\mathrm{CO})$}

Carbon monoxide is produced in the internal combustion engine due to incomplete combustion as a result of insufficient oxygen (Ashok et al., 2019; Kaisan et al., 2020b). It can be seen from Figure 15 that the addition of pentanol and Moringa Oleifera biodiesel to pure diesel has greatly reduced CO emission. B26P4 Blend have the lowest Carbon monoxide emission, it shows a reduction of $\mathrm{CO}$ emission of about $58 \%$ when compared with the pure diesels, but as the percentage of pentanol increases and that of biodiesels decreases within the blend, $\mathrm{CO}$ emission tend to increases slightly. This proves that biodiesel and pentanol can improve combustion quality of the fuel especially when an appropriate amount was used.

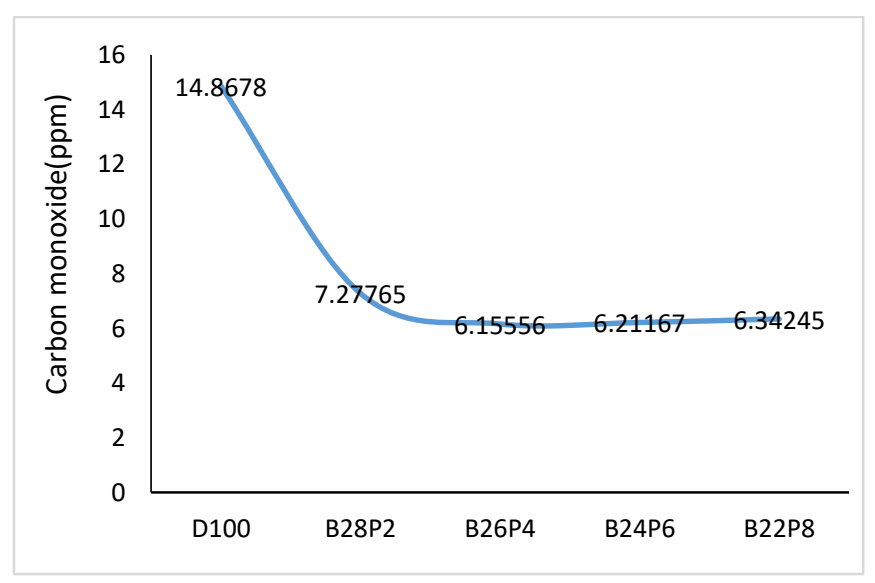

Figure 15: Carbon monoxide of the blends.

\section{CONCLUSION}

From the experimental results presented here, it is concluded that, addition of both Moringa oleifera biodiesel and pentanol on convectional diesel affect the combustion process. The B24P6 is the best blend in terms of engine performance showing best engine power, and engine brake thermal efficiency, of $19.78 \mathrm{~kW}$ and $19.7 \%$ respectively. However, in terms of engine emission of NOx, B22P8 has shown a favorable result with lowest Nitrogen oxide (NOx) emission, of about 3\% lower than that of the pure diesels.

Other blends that also shows promising results are B24P6 blend which have better carbon dioxide (CO2) emission with a percentage reduction of about $9 \%$ when compared with pure diesels while B26P4 have the lowest carbon monoxide (CO) emissions which a percentage reduction of $58 \%$ as compared to pure diesel. The entire blends performed well in terms of brake mean effective pressure. In general, it was concluded that the addition of Moringa oleifera biodiesel being an oxygenate reduces the engine emissions as compared to pure diesel. This finding will go a long way in selecting the best blends to use in solving current environmental problem resulting from the use of Petro diesel.

\section{REFERENCES}

Ashok, B.; A. K. Jeevanantham; K. Nanthagopal; K. Saravanan; M. S., Kumar; Johny, A. and Abubakar, S. (2019). An experimental analysis on the effect of $n$-pentanolCalophyllum Inophyllum Biodiesel binary blends in CI engine characteristcis. Energy, 173, 290-305.

Atabani, A. E.; M. Mofijur; H. H. Masjuki; I. A. Badruddin; Kalam, M. A. and Chong, W. T. (2014). Effect of Croton megalocarpus, Calophyllum inophyllum, Moringa oleifera, palm and coconut biodiesel-diesel blending on their physico-chemical properties. Industrial Crops and Products, 60, 130-137.

Campos-Fernandez, J.; J. M. Arnal; J. Gomez; Lacalle, N. and Dorado, M. P. (2013). Performance tests of a diesel engine fueled with pentanol/diesel fuel blends. Fuel, 107, 866-872.

Da Silva, J. P.; T. M. Serra; M., Gossmann; C.R., Wolf; Meneghetti, M. R. and Meneghetti, S. M. (2010). Moringa oleifera oil: studies of characterization and biodiesel production. Biomass and Bioenergy, 34(10), 1527-1530.

Damanik, N.; H. C. Ong; C. W., Tong; Mahlia, T. M. I. and \& Silitonga, A. S. (2018). A review on the engine performance and exhaust emission characteristics of diesel engines fueled with biodiesel blends. Environmental Science and Pollution Research, 25(16), 15307-15325.

Demirbas, A.; A. Bafail; Ahmad, W. and Sheikh, M. (2016). Biodiesel production from non-edible plant oils. Energy Exploration \& Exploitation, 34(2), 290-318.

Devarajan, Y.; babu M. D. \& Nagappan, B. (2017). Emissions analysis on diesel engine fueled with cashew nut shell biodiesel and pentanol blends. Environmental science and pollution research, 24(14), 13136-13141.

Kaisan, M. U.; F.O. Anafi; J. Nuszkowski; Kulla, D. M., and Umaru, S. (2017). Calorific value, flash point and cetane number of biodiesels from cotton, jatropha and neem binary and multi-blends with diesel. Biofuels. 11(3), 321-327. doi: 10.1080/17597269.2017.1358944.

Kaisan, M. U.; S. Abubakar; B. Ashok; D. B., Balasubramanian; S. Narayan; Grujic, I., and Stojanovic, N. (2018). Comparative analyses of biodiesel produced from jatropha and neem seed oil using a gas chromatography-mass spectroscopy technique. Biofuels, 1-12.

Kaisan, M. U.; S. Abubakar; F.O. Anafi; S. Umaru; P.M. Shameer; Umar, U. A., and Mary, J. S. (2020a). 
Modelling and Simulation of Biodiesel from Various Feedstocks into Compression Ignition Engine. In Energy Recovery Processes from Wastes (pp. 101-113). Springer, Singapore.

Kaisan, M. U.; S., Abubakar; S. Umaru; B. S., Dhinesh; P.M. Shameer; Sekar, K. and \& Mary, J. S. (2020b). Comparative Analysis of Experimental and Simulated Performance and Emissions of Compression Ignition Engine Using Biodiesel Blends. In Energy Recovery Processes from Wastes (pp. 85-100). Springer, Singapore.

Kaisan, M.U.; L.O. Yusuf; I.U. Ibrahim; Abubakar, S. and Narayan, S. (2020c). Effects of Propanol and Camphor Blended with Gasoline Fuel on the Performance and Emissions of a Spark Ignition Engine. ACS omega, 5(41), pp.2645426462.

Kaisan, M. U; A. Sanusi; Ibrahim, I.U. and Abubakar, S. (2020d). Effect of Butanol and Camphor Blended with Premium Motor Spirit on Performance and Emission of Spark Ignition Engine. Jurnal Mekanikal, 43, pp.77-94.
Mofijur, M.; H.H., Masjuki; M.A. Kalam; A. E.mAtabani; Fattah, I. R., and Mobarak, H. M. (2014). Comparative evaluation of performance and emission characteristics of Moringa oleifera and Palm oil based biodiesel in a diesel engine. Industrial crops and products, 53, 78-84.

Mofijur, M.; H. H. Masjuki; M.A. Kalam; M.G. Rasul; A.E. Atabani; Hazrat, M. A. and Mahmudul, H. M. (2015). Effect of biodiesel-diesel blending on physicochemical properties of biodiesel produced from Moringa oleifera. Procedia Engineering, 105(Icte 2014), 665-69.

Tubino, M. and Aricetti, J. A. (2013) 'A green potentiometric method for the determination of the iodine number of biodiesel', Fuel, 103, 1158-1163. doi: 10.1016/j.fuel.2012.10.011

Wei, L. ; Cheung, C. S., \& Huang, Z. (2014). Effect of npentanol addition on the combustion, performance and emission characteristics of a direct-injection diesel engine. Energy, 70, 172-180. 